Article

\title{
Regulation of Tomato Specialised Metabolism after Establishment of Symbiosis with the Endophytic Fungus Serendipita indica
}

\author{
Fani Ntana ${ }^{1}\left(\mathbb{D}\right.$, Sean R. Johnson ${ }^{2}$, Björn Hamberger ${ }^{3}$, Birgit Jensen ${ }^{1} \mathbb{D}$, Hans J. L. Jørgensen ${ }^{1}(\mathbb{D}$ \\ and David B. Collinge ${ }^{1, * \mathbb{D}}$ \\ 1 Department of Plant and Environmental Sciences and Copenhagen Plant Science Centre, \\ University of Copenhagen, Thorvaldsensvej 40, 1871 Copenhagen, Denmark; fntana@envs.au.dk (F.N.); \\ bje@plen.ku.dk (B.J.); hjo@plen.ku.dk (H.J.L.J.) \\ 2 New England Biolabs, Inc., 240 County Road, Ipswich, MA 01938, USA; sjohnson@neb.com \\ 3 Department of Biochemistry and Molecular Biology, Michigan State University, 603 Wilson Rd, \\ East Lansing, MI 48824, USA; hamberge@msu.edu \\ * Correspondence: dbc@plen.ku.dk; Tel.: +45-35333356
}

Citation: Ntana, F.; Johnson, S.R.; Hamberger, B.; Jensen, B.; Jørgensen, H.J.L.; Collinge, D.B. Regulation of Tomato Specialised Metabolism after Establishment of Symbiosis with the Endophytic Fungus Serendipita indica. Microorganisms 2022, 10, 194.

https://doi.org/10.3390/

microorganisms10010194

Academic Editors: Gustavo Santoyo, James White, Ajay Kumar and Virendra Mishra

Received: 15 December 2021

Accepted: 9 January 2022

Published: 16 January 2022

Publisher's Note: MDPI stays neutral with regard to jurisdictional claims in published maps and institutional affiliations.

Copyright: (c) 2022 by the authors. Licensee MDPI, Basel, Switzerland. This article is an open access article distributed under the terms and conditions of the Creative Commons Attribution (CC BY) license (https:/ / creativecommons.org/licenses/by/ $4.0 /)$.

\begin{abstract}
Specialised metabolites produced during plant-fungal associations often define how symbiosis between the plant and the fungus proceeds. They also play a role in the establishment of additional interactions between the symbionts and other organisms present in the niche. However, specialised metabolism and its products are sometimes overlooked when studying plant-microbe interactions. This limits our understanding of the specific symbiotic associations and potentially future perspectives of their application in agriculture. In this study, we used the interaction between the root endophyte Serendipita indica and tomato (Solanum lycopersicum) plants to explore how specialised metabolism of the host plant is regulated upon a mutualistic symbiotic association. To do so, tomato seedlings were inoculated with $S$. indica chlamydospores and subjected to RNAseq analysis. Gene expression of the main tomato specialised metabolism pathways was compared between roots and leaves of endophyte-colonised plants and tissues of endophyte-free plants. S. indica colonisation resulted in a strong transcriptional response in the leaves of colonised plants. Furthermore, the presence of the fungus in plant roots appears to induce expression of genes involved in the biosynthesis of lignin-derived compounds, polyacetylenes, and specific terpenes in both roots and leaves, whereas pathways producing glycoalkaloids and flavonoids were expressed in lower or basal levels.
\end{abstract}

Keywords: endophyte; glycoalkaloids; phenolics; polyacetylenes; Piriformospora indica; secondary metabolism; terpenes; tomato

\section{Introduction}

Fossils from the Early Devonian period displaying fungal-like structures inside plant cells provide evidence that plant-fungal interactions date back to more than 400 million years ago. In fact, it appears that these symbiotic interactions have contributed to the colonisation of land and the emergence of the first terrestrial plants [1-3]. Today, plant-fungal symbiosis is considered a dynamic interaction, ranging from mutualism and commensalism, to parasitism, depending on the result of the interaction on the plant host [4]. Mutualistic interactions in the soil are usually characterised by exchange of nutrients, during which the fungus acquires carbon from the host and, in return, it facilitates the acquisition and assimilation of essential and scarce soil elements (e.g., nitrogen, phosphorus, and iron) [3,5]. However, chemical crosstalk in plant-fungal symbioses is more complex and often serves multiple purposes. Plants produce defence molecules to fight pathogens or exude a variety of compounds to recruit beneficial fungi, while fungal symbionts synthesise metabolites to reprogram plant signalling and metabolism or antimicrobials to defend themselves 
from competing microorganisms [6-8]. Products of the specialised metabolism are often involved in these processes, shaping not only the actual plant-fungal symbiosis but also interactions with other organisms on a multitrophic level [9-13].

The root endophyte Serendipita indica (formerly known as Piriformospora indica, order Sebacinales, phylum Basidiomycota) has been extensively used in studying plant-fungal interactions [14-16]. S. indica is an axenically cultivable fungus, able to colonise a wide range of plant species. Colonisation by $S$. indica displays an unusual, biphasic pattern, according to which the fungus switches from the initial biotrophic growth to a necrotrophiclike behaviour, inducing programmed cell death in the roots $[17,18]$. During the early colonisation phase, S. indica secretes effector-like proteins and interferes with the plant hormone homeostasis to evade or suppress host defence [17-19]. Establishment of biotrophy at this stage is further assisted through the production of phytohormone analogues by the endophyte itself [20].

Colonisation by $S$. indica can promote plant growth and development [21,22] and enhance plant tolerance to biotic and abiotic stresses [23-25]. The exact mechanisms via which $S$. indica confers these benefits to the host are yet to be fully elucidated, but they appear to be related to the endophyte's ability to improve nutrient uptake and induce plant defence responses [26-28]. For example, association with S. indica causes accumulation of several plant specialised metabolites [21,29-32], compounds that are often implicated in defence mechanisms [33].

In this study, we investigated a mutualistic plant-fungal symbiosis focusing on the dynamics of specialised metabolism in the host plant. Tomato plants (Solanum lycopersicum) were used as hosts due to their importance as a vegetable crop (worldwide production of 180 million tonnes [34]) and their well-characterised specialised metabolism [35-37]. In detail, roots and leaves of $S$. indica-colonised and endophyte-free tomato plants were subjected to a whole-transcriptome analysis using RNAseq. Our results showed that the presence of $S$. indica in the roots led to a strong transcriptional response in the leaves of colonised plants, which has not been reported before. In addition, we observed that $S$. indica colonisation caused accumulation of transcripts from genes involved in the biosynthesis of lignin-derived compounds, polyacetylenes, and specific terpenes in roots and leaves, while pathways producing glycoalkaloids and flavonoids were downregulated or left unaffected.

\section{Materials and Methods}

\subsection{Fungal and Plant Material}

Serendipita indica (isolate DSM11827) was cultured on solid complete medium (CM) plates supplemented with $1.5 \%(w / v)$ agar (Aspergillus medium, [38]) at $28^{\circ} \mathrm{C}$.

Tomato seeds (Solanum lycopersicum, cv. Moneymaker) were surface sterilised (1 min in $70 \%$ ethanol, $10 \mathrm{~min}$ in $1 \% \mathrm{NaClO}(v / v)$ ), rinsed multiple times with sterile MilliQ water, and then transferred in a growth chamber $\left(12 \mathrm{~h}\right.$ day $22^{\circ} \mathrm{C} / 12 \mathrm{~h}$ night $18^{\circ} \mathrm{C}, 120 \mu \mathrm{E} / \mathrm{m}^{2} \cdot \mathrm{s}$ light intensity, $60 \%$ relative humidity) until fully germinated (11 days). Tomato seedlings were incubated in a $S$. indica chlamydospore suspension $(40 \mathrm{~mL}$ with a concentration of 300,000 chlamydospores $/ \mathrm{mL}$ ) overnight, on a shaker (120 rpm) at room temperature. For the control treatment, tomato seedlings were incubated in sterile water. Control and S. indica-inoculated seedlings were sown on Murashige-Skoog (MS) basal medium (SigmaAldrich, St. Louis, MO, USA), supplemented with $1.5 \%(w / v)$ agar and grown in the same growth chamber until harvest.

\subsection{RNA Isolation from Tomato Leaves and Roots and RNA Sequencing}

Tomato seedlings were harvested $11 \mathrm{dpi}$ (days post inoculation) and roots and leaves (first and second true leaves) were sampled separately. Tissues from seven plants were pooled in one biological replication, and four biological replications were included for each treatment and each tissue. Before RNA extraction, the samples were freeze-dried overnight to facilitate milling. Total RNA was extracted using the Spectrum ${ }^{\mathrm{TM}}$ Plant Total RNA Kit (Sigma-Aldrich, St. Louis, MO, USA) according to the manufacturer's instructions, and the samples were 
sent for sequencing to Novogene Bioinformatics Technology Co. Ltd. (Hong Kong). After sample RNA quality and integrity were verified on an Agilent 2100 Bioanalyser, 16 libraries (four biological replications per treatment per tissue) were constructed and processed by Illumina HiSeq sequencer. Sequencing was done on 150 bp paired-end reads, generating $\geq 30$ million reads per sample (Supplementary Table S1). The raw reads were deposited in NCBI's Sequence Read Archive (SRA) under the BioProject accession number PRJNA789108 (https: / / www.ncbi.nlm.nih.gov/bioproject/PRJNA789108).

\subsection{Bioinformatic Analysis, Differential Expression, and Gene Ontology Enrichment Analysis}

Raw reads were filtered to remove adapter sequences or reads of low quality using BBDuk [39]. Salmon version 0.12.0 [40] was used to estimate the abundance of Solanum lycopersicum transcripts (gene models from ITAG3.2), available in [41]. Differential expression analysis was performed with Deseq2 version 3.8 (false discovery rate, FDR $<0.1$ ) [42]. Genes with an FDR-corrected $p \leq 0.05$ were considered differentially expressed. The logarithmic fold change of gene expression between the treated and the control samples was used for comparative analysis of the data (supplementary file: DESeq2 analysis). Expression of genes involved in the main tomato metabolic pathways was presented in the form of a heatmap using R Studio.

Plant MetGenMAP package [43] was used to identify the enriched Gene Ontology (GO) terms related to biological processes that the differentially expressed genes belong to. Only the genes that were two-fold differentially expressed were used, and only the GO terms that were significantly enriched with a simulation-corrected $p \leq 0.05$ were considered (Supplementary Table S2-S6). Visualisation of selected GO enrichment analysis results was performed with R Studio [44] and scripts were generated by REVIGO [45].

Phytohormone biosynthesis, signalling, and specialised metabolism pathways of S. lycopersicum were assembled using a gene-by-gene approach, combining data from previously published literature and expression data from our study (Supplementary Table S6-S16).

\section{Results}

\subsection{Summary of RNAseq Data and Differential Gene Expression Analysis}

Of the reads from each sample, $80-87 \%$ were mapped to the tomato transcriptome (Solanum lycopersicum gene models ITAG3.2) (Supplementary Table S1). After comparing expression data between leaves of colonised and control plants, we found 6138 genes differentially expressed (FDR corrected $p \leq 0.05$ ), among which the expression of 1259 genes was at least two-fold changed (391 genes upregulated and 868 downregulated). In the roots, only the transcript levels of 957 genes were affected, and almost one-third of them (300 genes) were expressed with a fold change equal or higher than two after colonisation (128 genes upregulated and 172 genes downregulated) (Figure 1).

\subsection{GO Term Enrichment Analysis}

Only the differential expressed genes in leaves and roots with at least two-fold change in expression were used for the GO term enrichment analysis. The most significantly overrepresented GO terms among the upregulated genes in leaves were associated with RNA processing, ribosome biogenesis, and nuclear transport (GO:0042254 ribosome biogenesis, GO:0006364 rRNA processing, GO:0034470 ncRNA processing, GO:0006606 protein import into nucleus) (Supplementary Figure S1A, Supplementary Table S2). Regarding downregulated genes in leaves, the most significant enrichment in biological processes involved the wide category of transcription regulation (GO:0003700 DNA-binding transcription factor activity, GO:0030528 obsolete transcription regulator activity) (Supplementary Figure S1B, Supplementary Table S3). 


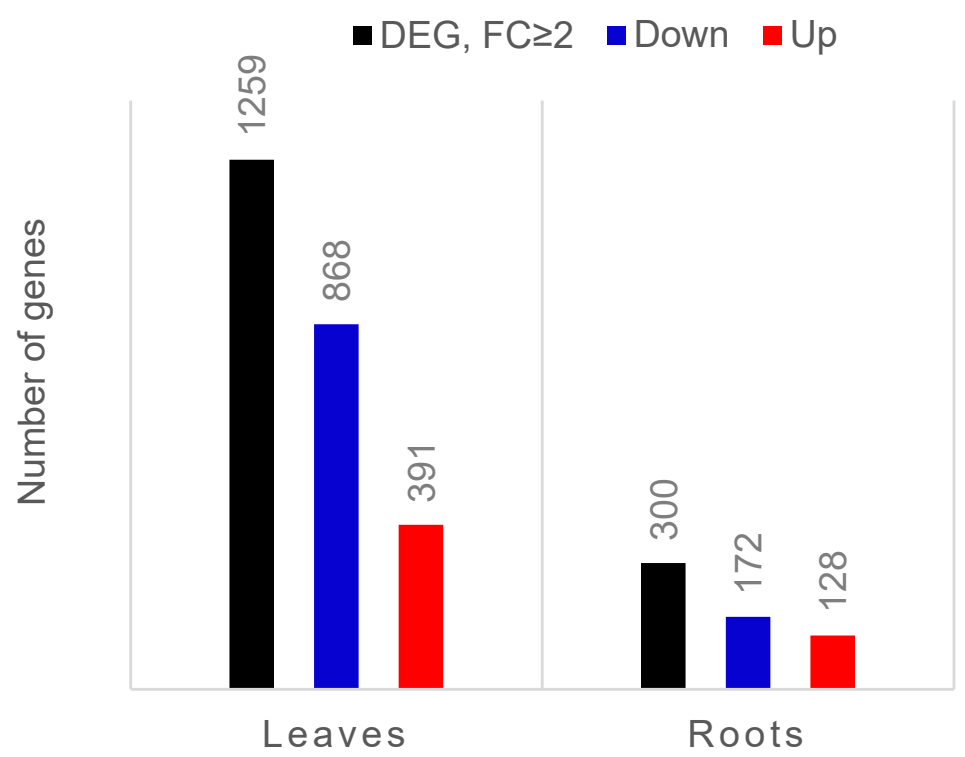

Figure 1. Bar chart showing the number of differentially expressed genes (DEGs; FDR-corrected $p$-value $\leq 0.05)$ in leaves and roots of endophyte-colonised compared to endophyte-free tomato plants. The black bars represent the total number of DEGs that exhibited at least two-fold changed expression (FC $\geq 2$ ). Upregulated genes are marked in red and downregulated genes are marked in blue.

Some of the most significantly enriched GO terms (simulation-corrected $p \leq 0.005$ ) among the root upregulated genes belonged to processes related to defence (GO:0031347 regulation of defence response, GO:0010200 response to chitin) and plant immunity (GO:0045087 innate immune response, GO:0009627 systemic acquired resistance). Other enriched GO categories (simulation corrected $p \leq 0.05$ ) were associated with hormone biosynthesis and signalling (GO:0009863 salicylic acid-mediated signalling pathway, GO:0042446 hormone biosynthetic process, GO:0009867 jasmonic acid-mediated signalling pathway), as well as programmed cell death (PCD) (GO:0010363 regulation of plant-type hypersensitive response, GO:0043067 regulation of programmed cell death) and nitrogen starvation processes (GO:0006995) (Supplementary Figure S2A, Supplementary Table S4). The most significantly over-represented GO terms among the downregulated genes in the roots were biological processes relevant to abiotic stress responses (GO:0009314 response to radiation, GO:0009416 response to light stimulus, GO:0009628 response to abiotic stimulus), as well as phenylpropanoid and flavonoid biosynthesis (GO:0009699 phenylpropanoid biosynthetic process, GO:0009813 flavonoid biosynthetic process) (Supplementary Figure S2B, Supplementary Table S5).

\subsection{S. indica Root Colonisation Downregulates Glycoalkaloid Biosynthetic Genes in Tomato Leaves}

The presence of $S$. indica in the roots of tomato plants resulted in downregulation of most of the genes involved in the synthesis of steroidal glycoalkaloids in leaves. The pathway leading to cholesterol, the steroidal glycoalkaloid precursor, and their core pathway (GAME: glycoalkaloid metabolism genes) were found to be less expressed in leaves of colonised plants compared to the leaves of control plants. However, only minor changes were observed in the roots, the place of the direct plant-endophyte interaction, where only GAME12 and GAME7 showed significant downregulation due to fungal colonisation (Figure 2, Supplementary Table S6). 


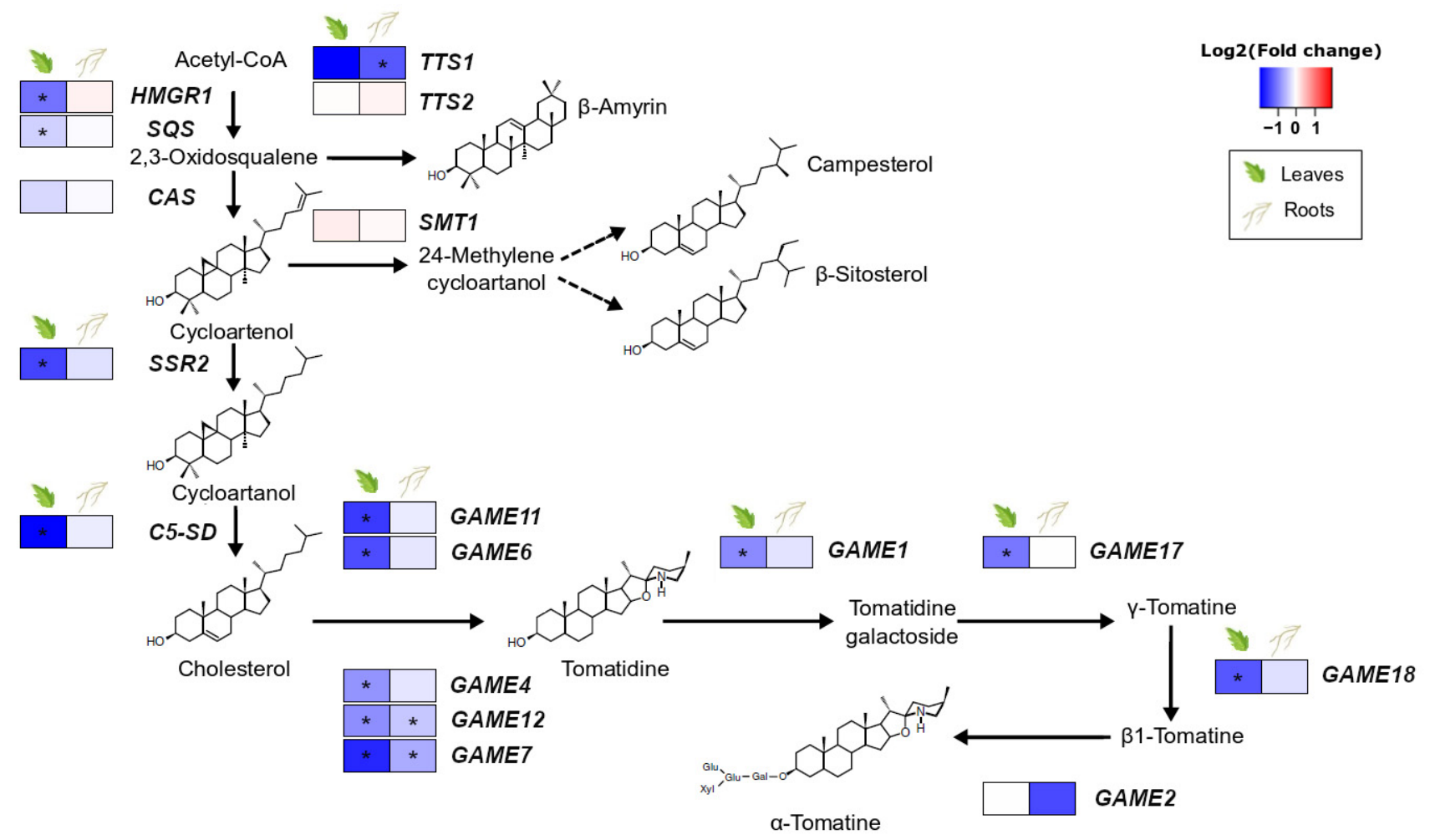

Figure 2. Effect of $S$. indica colonisation on the expression of genes involved in the biosynthetic pathway of sterol precursors and glycoalkaloids in tomato leaves and roots. Changes in gene expression between tissues from inoculated plants and tissues from endophyte-free plants are represented as $\log _{2}$ of the fold change in the form of a heatmap. Data derived from RNA sequencing of leaves and roots from $S$. indica-colonised and endophyte-free plants. Asterisks $\left(^{*}\right)$ indicate FDR-corrected $p \leq 0.05$. HMGR1, 3-hydroxy-3-methylglutaryl-CoA reductase; SQS, squalene synthase; CAS, cycloartenol synthase; SSR2, sterol side-chain reductase 2; C5/SD, $\Delta(7)$-sterol-C5-desaturase; TTS1, triterpenoid synthase 1; TTS2, triterpenoid synthase 2; SMT, sterol methyltransferase; adaptedfrom [46-48].

\subsection{Effect of S. indica Colonisation on Tomato Phenylpropanoid-Related Genes}

S. indica colonisation barely modulated biosynthesis of phenolic compounds in both leaves and roots of tomato plants. The majority of the genes involved in the phenylpropanoid core pathway, as well as the genes involved specifically in the biosynthesis of flavonoids, flavonols, and anthocyanins, were either downregulated or not affected at all by S. indica. However, C3H1 and $p C S E$, which direct the flux into the biosynthetic pathway of lignin and hydroxycinnamic acids (HCAs), were the only two genes significantly upregulated by the presence of the fungus in both tissues (Figure 3, Supplementary Tables S7-S9).

\subsection{S. indica Upregulates Genes Involved in the Biosynthesis of Highly Modified Fatty Acids in Tomato}

Among the 41 genes annotated as putative fatty-acid desaturases (FADs) in the tomato genome, seven genes in the roots and four in the leaves of colonised plants were significantly upregulated (Figure 4A). Although FADs are implicated in multiple physiological processes in plants (e.g., energy storage, membrane formation, hormone biosynthesis), the specific FADs found upregulated in tissues of colonised plants (Figure $4 \mathrm{~B}$ ) belong to a recently discovered gene cluster in tomato, responsible for the production of falcarindiol, a prototypical acetylenic lipid with antifungal properties [51]. 


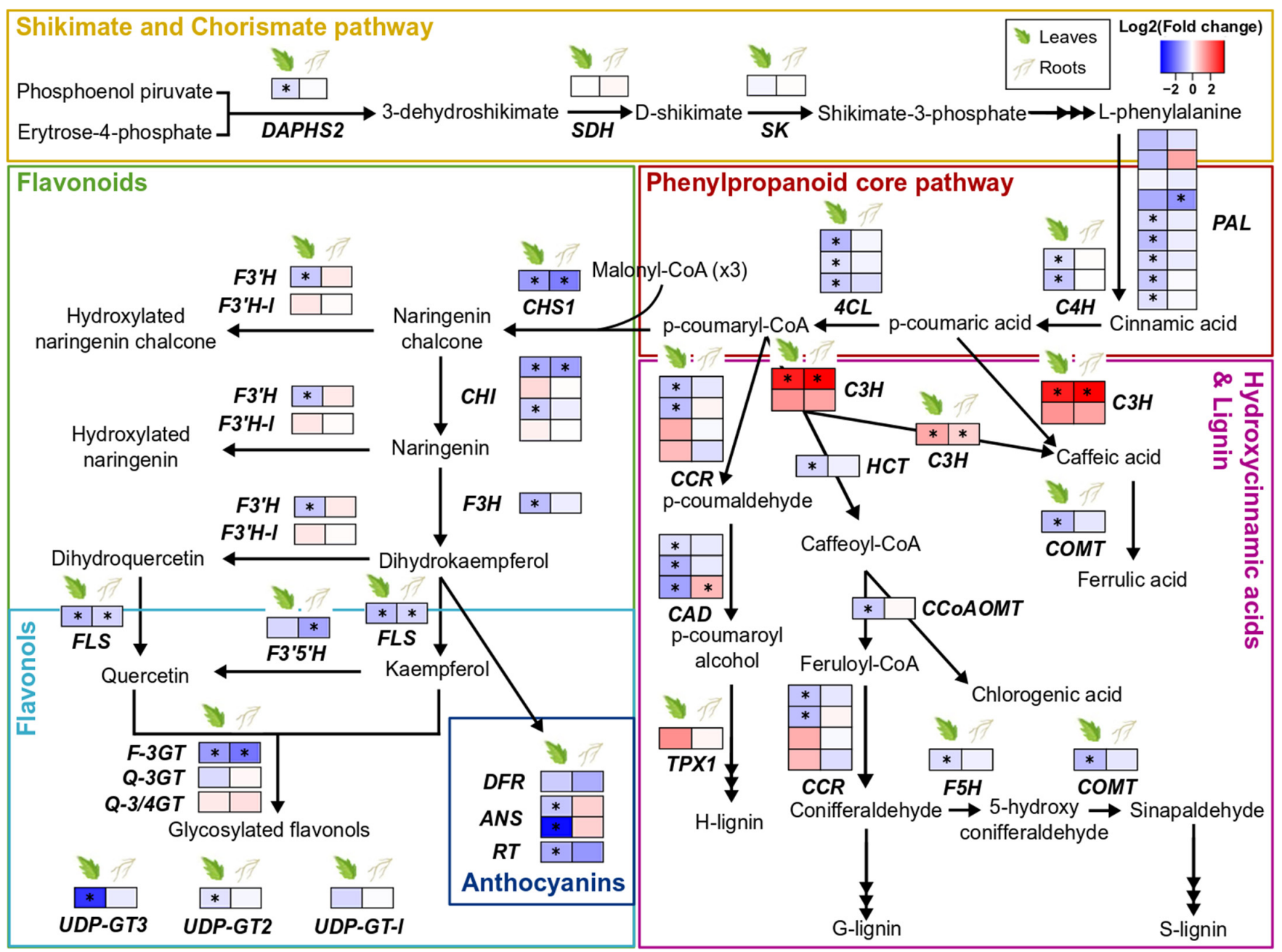

Figure 3. Changes in gene expression of phenylpropanoid biosynthetic pathways due to S. indica-colonisation in tomato leaves and roots. Key genes involved in the biosynthesis of shikimate and chorismate, flavonoids, flavonols, anthocyanins, hydroxycinnamic acids, and lignin are shown here. Changes in gene expression between tissues from inoculated plants and tissues from endophyte-free plants are represented as $\log _{2}$ of the fold change in the form of a heatmap. Asterisks $\left({ }^{*}\right)$ indicate FDR-corrected $p \leq 0.05$. DAHPS2, DAHP synthase 2; $\mathrm{SDH}$, shikimate 5-dehydrogenase; SK, shikimate kinase; PAL, phenylalanine ammonia lyase; $\mathrm{C} 4 \mathrm{H}$, cinnamate 4-hydroxylase; 4CL, 4-coumarate:CoA ligase; $\mathrm{CHS1}$, chalcone synthase 1; F3' $\mathrm{H}$, flavonoid-3'-hydroxylase; F3' $\mathrm{H}$-1, flavonoid-3'-hydroxylase-like; $\mathrm{CHI}$, chalcone isomerase; $\mathrm{F} 3 \mathrm{H}$, flavanone-3-hydroxylase; FLS, flavonol synthase; F3' $5^{\prime} \mathrm{H}$, flavonoid-3 $3^{\prime} 5^{\prime}$-hydroxylase; F-3GT, flavonol 3-glycosyltransferase; Q-3GT, quercetin 3-glycosyltransferase; Q-3/4GT, quercetin 3/4glycosyltransferase; UDP-GT3, UDP-glycosyltransferase 3; UDP-GT2, UDP-glycosyltransferase 2; UDP-GT-1, UDP-glycosyltransferase-like; DFR, dihydroflavonol reductase; ANS, anthocyanidin synthase; RT, anthocyanin 3-glycosyltransferase; CCR, cinnamoyl-CoA reductase; HCT, hydroxycinnamoyl transferase; CAD, cinnamyl alcohol dehydrogenase; TPX1, tomato peroxidase $1 ; \mathrm{C} 3 \mathrm{H}$, p-coumaroyl 3-hydroxylase; pCSE, putative caffeoyl shikimate esterase; COMT, caffeic acid $\mathrm{O}$-methyltransferase; CoAOMT, caffeoyl CoA 3-O-methyltransferase; F5H, coniferyl aldehyde 5-hydroxylase; adapted from [49,50]. 
A

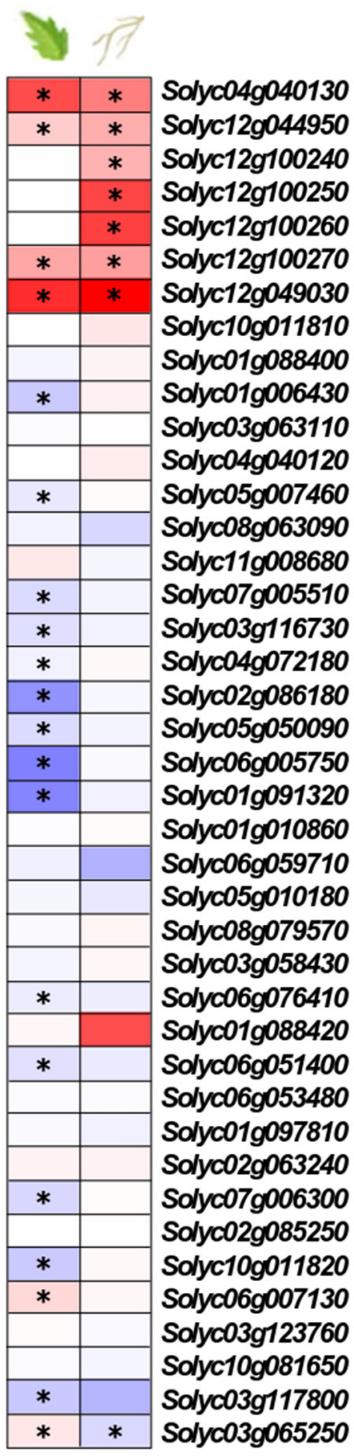

B

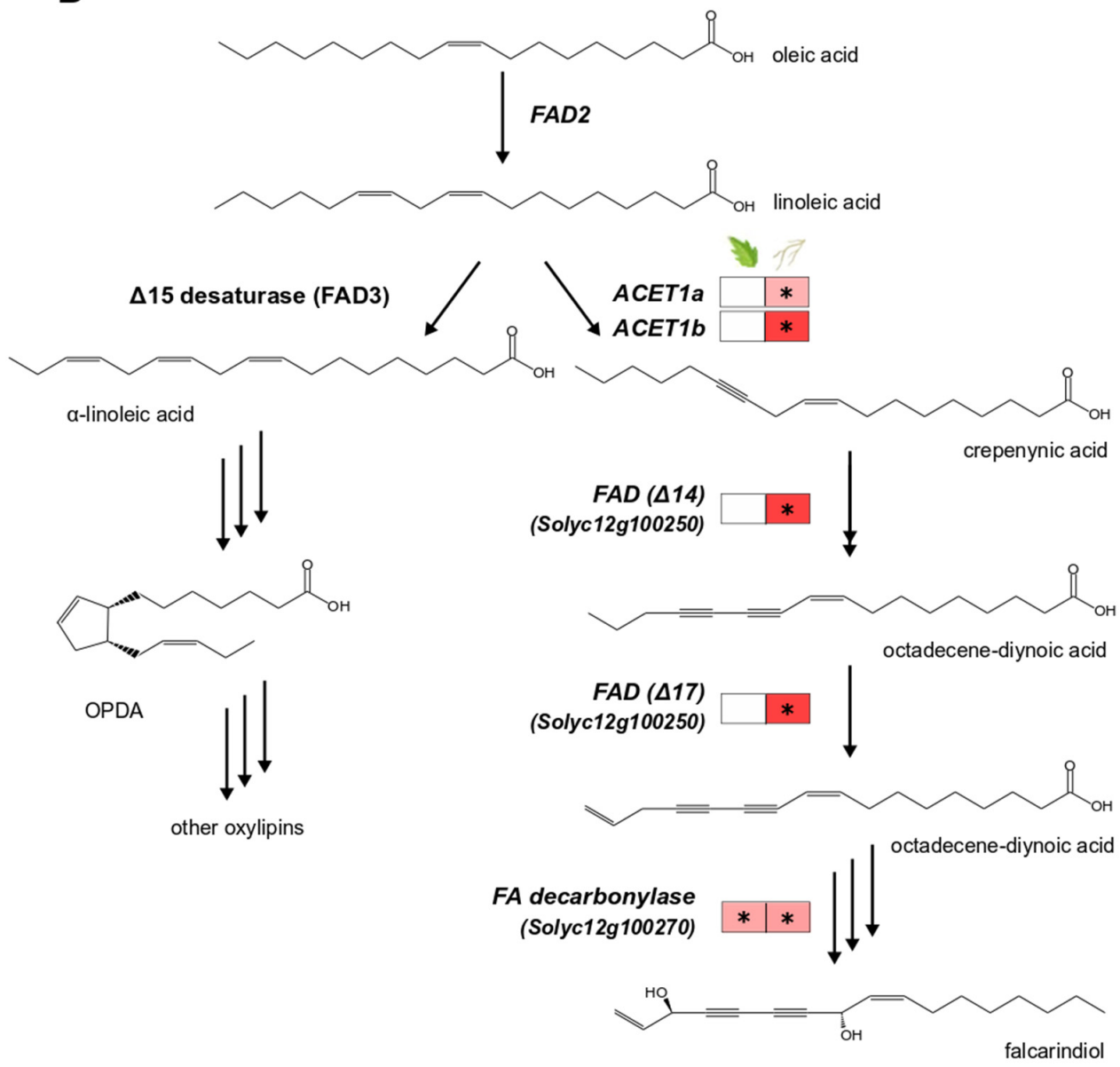

Figure 4. Tomato putative fatty-acid desaturases (FADs) involved in the biosynthesis of fatty acids in leaves and roots. (A). Changes in gene expression between tissues from inoculated plants and tissues from endophyte-free plants are represented as $\log _{2}$ of the fold change in the form of a heatmap. Data derived from RNA sequencing on leaves and roots from S. indica- and mock-inoculated plants. Asterisks ${ }^{*}$ ) indicate FDR-corrected $p \leq 0.05$. (B). Biosynthetic pathway leading to oxylipins (left) and falcarindiol (right). Linoleic acid is used in the biosynthesis of jasmonic acid and other oxylipins, as well as the production of highly modified fatty acids (polyacetylenes). Proposed chemical structures, gene function and biosynthetic pathway are based on the work of [51].

\subsection{S. indica Changes Expression of TPSs in Tomato Leaves and Roots}

Root colonisation by $S$. indica only affected specific terpene synthase genes (TPSs) (Figure 5A, Supplementary Table S13) and transcription factors (Supplementary Table S14) potentially involved in terpenoid metabolism. Specifically, TPS5 and TPS9, involved in linalool and germacrene $C$ synthesis, respectively, were found to be downregulated in leaves of $S$. indica-colonised plants. On the contrary, we observed a high abundance of transcripts from TPS51, involved in the production of several sesquiterpenes ( $\alpha$-bisabolol, $(Z)$-nerolidol, $\alpha$-bisabolene, $\beta$-bisabolene, and (Z)- $\beta$-farnesene) [52] in the leaves of colonised plants. 
A

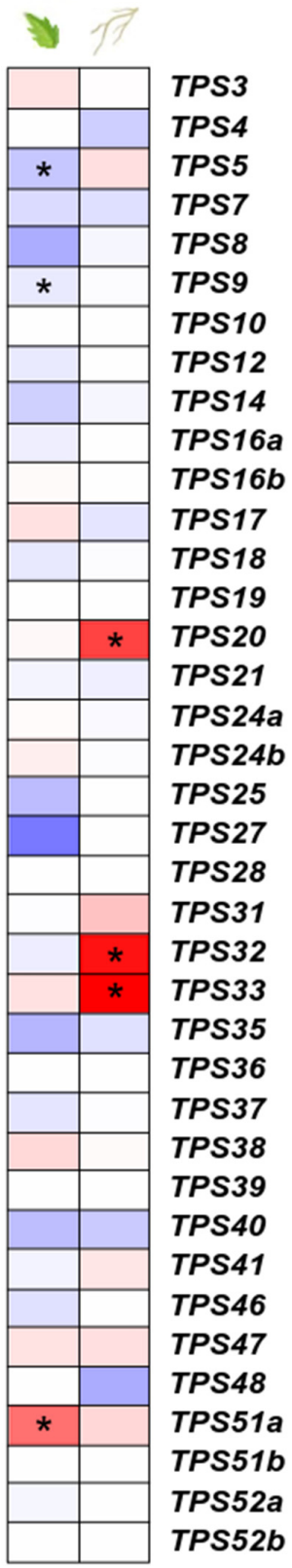

B

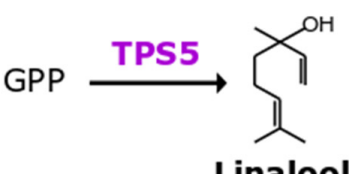

Linalool

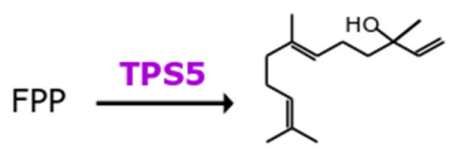

E-Nerolidol

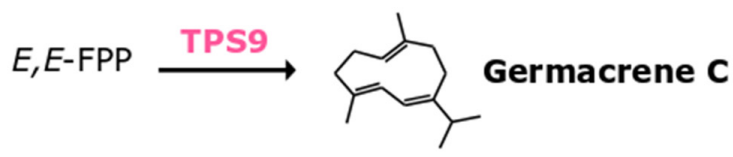

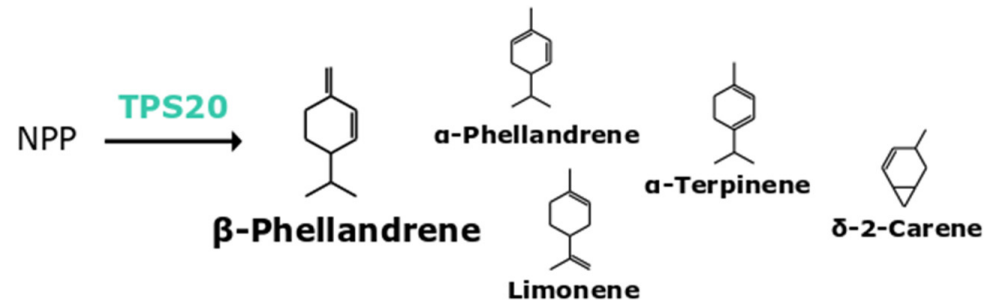<smiles>CC1=C2CCC(C(C)C)C(C(C)(C)C)C2CCC(C(F)(F)F)=P1</smiles>

Viridiflorene

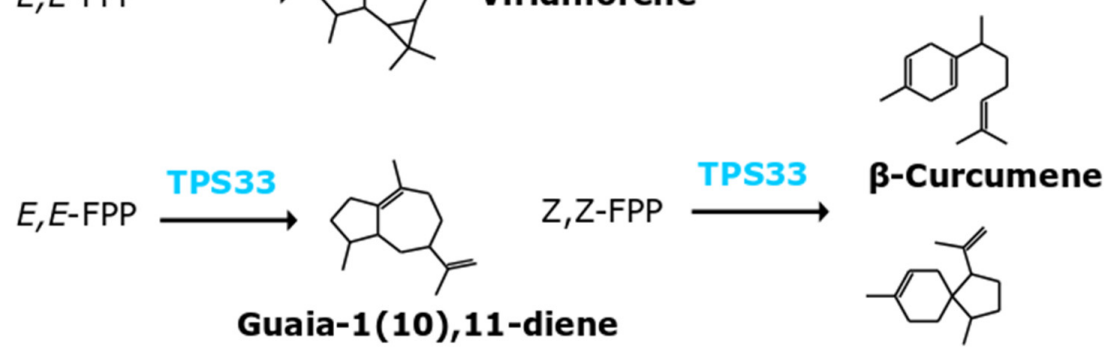

Guaia-1(10),11-diene

\section{$\beta$-Acoradiene}
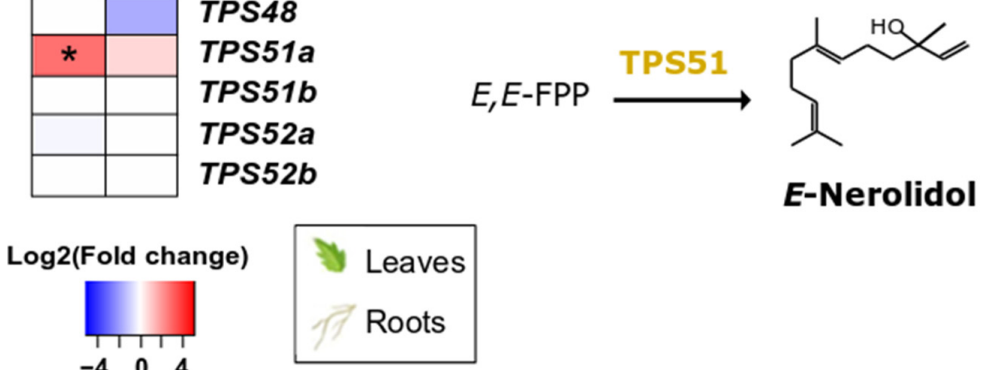

Figure 5. The tomato TPS family. (A). Effect of S. indica colonisation on the expression of tomato TPSs in leaves and roots. Changes in gene expression between tissues from inoculated plants and tissues from endophyte-free plants are represented as $\log 2$ of the fold change in the form of a heatmap. Data derived from RNA sequencing on leaves and roots from S. indica- and mock-inoculated plants. Asterisks $\left({ }^{*}\right)$ indicate FDR-corrected $p \leq 0.05$, apart from TPS32 and TPS33, whichwere expressed only in samples from inoculated roots, and no related transcripts were found in the samples of control roots. (B). Biosynthetic pathways catalysed by the TPSs, the expression of which is affected by $S$. indica colonisation, are only presented here. Main products of the enzymatic reactions are shown in regular font size, while terpenoids detected as minor peaks are shown in a smaller size. Reactions are drawn based on data from in vitro enzymatic assays from [52-56]. 
S. indica also induced transcript accumulation of three terpene synthase genes (TPS20, TPS32, TPS33) in tomato roots (Figure 5, Supplementary Table S13). TPS20 encodes for an enzyme that produces mainly $\beta$-phellandrene and a mixture of other monoterpenes [53]. According to [54], TPS32 catalyses the formation of viridiflorene and several unidentified sesquiterpenes, whilst TPS33 forms several sesquiterpenes such as guaia-1(10),11-diene and $\beta$-acoradiene [52].

\section{Discussion}

\subsection{Root Colonisation by S. indica Strongly Affected the Leaf Transcriptome}

The effect of $S$. indica colonisation on the tomato transcriptome was studiedin tomato roots, the place of the direct interaction, and simultaneously in the leaves. To our knowledge, this is the first study where this approach was followed to investigate a microbial interaction with tomato plants. On the 11th day after inoculation with the endophyte, a total of 957 genes were found to be differentially expressed in the roots of tomato plants, while surprisingly approximately six times more genes (6138) were affected in the leaves. Endophytic root colonisation resulted in a major transcriptional response in the leaves, an unexpected observation since previous studies suggested that the endophyte barely affects aerial parts of colonised plants, in the absence of any other challenge $[57,58]$. Discrepancies between our results and results from earlier reports could be ascribed to differences between experimental setups and sampling points or the use of more sensitive techniques for studying transcriptional changes (RNAseq instead of microarrays). Unfortunately, there is a gap in studying simultaneously transcriptional responses of below- and aboveground parts of plants associated with microorganisms. More studies investigating the effect of endophytic colonisation not only at the site of the direct interaction, but also at distant host tissues are necessary to unravel its complexity and potential.

\subsection{GO Term Enrichment Analysis in Roots Indicates S. indica Lifestyle and Colonisation Phase}

The GO term analysis of the leaf data did not give any obvious information about the biological processes affected in the aerial parts of the plant by S. indica colonisation. It is possible, however, that enrichment of upregulated genes in categories such as RNA processing, ribosome biogenesis, and nuclear transport, usually enhanced during cell proliferation and plant development [59], could indicate shoot growth promotion due to the presence of $S$. indica as reported in previous studies [21,23]. On the contrary, GO term analysis in roots showed that, in addition to defence and biotic stress responses, categories such as programmed cell death, hypersensitive response (HR), and respiratory burst responses against pathogen attacks were overrepresented in root upregulated genes. It has been previously shown that root colonisation by $S$. indica displays an unusual, biphasic pattern, during which the fungus biotrophically colonises the root in the early stages of infection (1-2 dpi), while, in later stages, a switch to a necrotrophic-like behaviour is observed, with the fungus proliferating and sporulation in dead root cells [17,18]. In accordance with this, the GO term analysis results indicated that, at the specific sampling point in the experiment (11 dpi), S. indica has already entered its necrotrophic phase of colonisation, upregulating genes involved in programmed cell death responses.

\subsection{S. indica Negatively Regulates Glycoalkaloid Biosynthesis in Leaves of Colonised Plants}

Steroidal alkaloids and steroidal glycoalkaloids are nitrogen-containing compounds, produced by solanaceous plants and involved in plant defence against pathogens and pests $[60,61]$. The most abundant steroidal alkaloids in tomato green tissues are $\alpha$-tomatine and its precursor dehydrotomatine [62] and the main enzymes and genes involved in their biosynthesis have been identified [46-48].

Our gene-by-gene approach of studying thetomato specialised metabolism showed that $S$. indica colonisation resulted in a decreased expression of the genes of cholesterol biosynthesis and the GAME (glycoalkaloid metabolism) genes involved in glycoalkaloid production in the leaves of tomato plants. One of the genes downregulated was GAME9 
(Supplementary Table S6), an APetala2/ethylene-responsive factor (AP2/ERF) transcription factor that regulates the biosynthesis of these compounds in Solanaceae plants [47]. In Catharanthus roseus, biosynthesis of terpenoid indole alkaloids is also regulated by an AP2/ERF MeJA-responsive transcription factor, ORCA3. CrMYC2 is the major activator of ORCA3 expression, and knocking it down results in a reduction in ORCA3 transcript levels [63]. A similar mechanism linking SIMYC2, GAME9, and alkaloids is also proposed for tomato [47]. S. indica causes SIMYC2 (Solyc08g076930.1.1) downregulation (Supplementary Table S18, fold change $=-0.71$, FDR-corrected $p \leq 0.05$ ) in the leaves of colonised plants, due to a general suppression observed in the JA pathway. This possibly also causes GAME9 downregulation and, thus, the decreased expression of the full SGA biosynthetic machinery. Regarding the roots, the expression of only two glycoalkaloid-related genes was negatively affected. Low levels of $\alpha$-tomatine and its precursor in colonised roots could allow for the expansion of the fungus since both compounds act against many fungi [62].

In a broader view, regulation of glycoalkaloid production has been connected with nitrogen availability in many plants [64]. According to our analysis, genes involved in nitrogen starvation responses are among the most enriched categories in the root upregulated genes (Figure S1A-GO:0006995, cellular response to nitrogen starvation), indicating that $S$. indica colonisation causes nitrogen depletion in the roots of tomato plants. This decrease in nitrogen levels, also observed in S. indica-colonised barley plants [65], could have generated signals, sent throughout the plant, in order to save up host nitrogen resources by suppressing related pathways, including glycoalkaloid biosynthesis.

\subsection{S. indica Colonisation Causes Downregulation of Most Phenylpropanoid Biosynthetic Genes in Leaves of Tomato Plants}

Phenylpropanoid compounds comprise a diverse group of plant specialised metabolites, also found in tomato. Phenylpropanoids include several groups of compounds such as flavonoids and flavonols, lignans, hydroxycinnamic acids, and their derivatives. In tomato, these compounds play various roles, serving in abiotic stress tolerance (flavonols) [49] or acting as antioxidants (chlorogenic acid) [66] and structural components (lignin and suberin) [67].

The GO term enrichment analysis showed that processes related to phenylpropanoid and flavonoid biosynthesis were two of the most over-represented categories among the root downregulated genes (Figure S2B). Following a more detailed study of some of the individual genes involved, we sawthat the fungus causes slight downregulation of the phenylpropanoid and related pathways, e.g., flavonoids, flavonols, and anthocyanins, mainly in the leaves of colonised plants (Figure 3, Supplementary Tables S7 and S8). The only two genes upregulated, in both roots and leaves, were C3H and CSE (Figure 3, Supplementary Table S9). These genes encode enzymes that use $p$-coumaric acid and $p$ coumaroyl-CoA, respectively, to synthesise hydroxycinnamic acids, which could be further used in lignin biosynthesis.

Our results do not align with other studies showing that endophytic colonisation by $S$. indica can induce production of some phenylpropanoids $[21,58,68]$. According to a nontargeted analysis done on several tissues of Arabidopsis plants inoculated with S. indica (14 dpi), the phenylpropanoid pathway was among the most enriched transcriptionally up-regulated KEGG pathways and several compounds (coumarins, oligolignols, and flavonoids) accumulated in the metabolite profiles of colonised roots. However, only oligolignols and hydroxycinnamic acid amides, and not flavonoids, were overproduced in leaves of colonised plants. Due to this observation, it was concluded that flavonoids are important key players in the A. thaliana and S. indica mutualistic interaction [58], which may not apply for the association of $S$. indica with tomato, a plant with a very different specialised metabolism. In addition, our data represent only a snapshot of the regulation of plant metabolism, and more sampling points may be necessary to shed light to whether these changes in gene expression are species-specific or time-related. In accordance with our findings on the increased accumulation of transcripts related to lignin and HCAs biosynthesis, lignan 
podophyllotoxin and several phenolic acids were found accumulated in hairy roots of Linum album that were treated with $S$. indica mycelium extract [69]. Increased flux towards the production of these phenolic compounds appears to be more consistent across the different host species $[32,58,69]$, indicating a generalised response to $S$. indica colonisation. This response could be further associated with defence mechanisms or enhanced water use efficiency and drought tolerance, through xylem strengthening, previously observed in S. indica-colonised plants [21].

\subsection{Genes Involved in Tomato Polyacetylene Biosynthesis Are Induced by S. indica}

A group of transcripts annotated as fatty acid desaturases (FADs) were among the most upregulated genes in colonised tomato roots (Figure 4A, Supplementary Table S10). Initially, these genes were considered to be involved in oxylipin and jasmonate biosynthesis, a response generally induced by $S$. indica colonisation and previously observed $[19,68]$. However, since our data suggested that JA biosynthesis and signalling were not affected at transcriptional level by the colonisation (Supplementary Figure S3, Supplementary Tables S15 and S16), we investigated the role of these genes in other pathways.

In [70], the biosynthetic steps of carrot polyacetylenes, lipid compounds produced after pathogen attack, were elucidated. Although polyacetylenes are produced mainly in the Apiaceae and Araliaceae families, the polyacetylenic products falcarindiol and falcarinol have been also detected in the leaves of domesticated tomatoes after infection by the fungus Cladosporium fulvum. Due to their antifungal activities, these compounds are considered to act in plant defence [35]. The biosynthetic pathway of acetylenic fatty acids shares the same starting point as linolenate and oxylipin biosynthesis. However, instead of the oleate conversion to linolenate by a $\Delta 12$ fatty acid desaturase (FAD), "divergent" FADs add unusual functional groups into the acyl chain (epoxyl or hydroxyl groups, conjugated double bonds, triple bonds), resulting in these highly modified fatty acids [71]. According to the recently elucidated biosynthetic steps of tomato polyacetylenes [51], the FADs found upregulated by $S$. indica colonisation belong to this group of these "divergent" enzymes, involved in the production of specialised metabolites (e.g., falcarinol and falcarindiolin) (Figure 4B). This could be an indication that the plant induces production of antifungal compounds in the roots in order to stop extensive growth of $S$. indica. In addition, this study shows that expression of this biosynthetic gene cluster can also be activated by a non-pathogenic fungus, which has not been reported previously.

\subsection{Expression of a Recently Described TPS Is Induced in the Leaves of S. indica-Colonised Plants}

One additional group of genes affected in fungal colonised plants belonged to the terpene biosynthetic pathway. Terpenes are classified as mono- (C10), sesqui- (C15), di(C20), tri-terpenes (C30), etc., depending on the number of carbon atoms they are composed of. Terpenes can contribute to plant direct [72] or indirect defences [73]. Biosynthesis of tomato terpenes has been extensively studied in tomato with key enzymes and transcription factors of the pathway widely identified [52-56,74-77].

The presence of $S$. indica was found to affect only specific TPSs in roots and leaves (Figure 5A, Supplementary Table S13). In colonised roots, the upregulated TPS20 encodes a $\beta$-phellandrene synthase that produces, together with $\beta$-phellandrene, a mixture of other monoterpenes [53]. Two more genes, localised in close proximity on chromosome 1, were expressed in the colonised roots, i.e., TPS32 and TPS33. The specific genes were also found to be upregulated in tomato fruits from plants colonised by arbuscular mycorrhizal fungi [78]. In addition to the biosynthesis of several sesquiterpenes that they individually catalyse, TPS32 and TPS33 (together with TPS31) comprise a biosynthetic cluster considered to be involved in the synthesis of rishitin, a tomato defence compound [78]. This hypothesis is further supported by the fact that the amino-acid sequences of these genes are closely related to the pepper 5-epi-aristolochenesynthase (EAS) involved in capsidiol biosynthesis, the main defence metabolite produced in peppers, equivalent to rishitin. In addition, we found a gene overexpressed in colonised roots (Solyc11g007980.2.1), which is the closest 
orthologue of the Capsicum annuum 5-epi-aristolochene-1,3-dihydroxylase gene (EAH) in tomato, and also involved in the same pathway [79].

Another study implicated high expression of TPS31, TPS32, TPS33, and TPS35 in leaves with increased resistance to Ralstonia solanacearum in the tomato cultivar H7996. In the same study, silencing of these genes in tomato plants resulted in an increased proliferation of $R$. solanacearum compared to control plants also infected with the bacterium, but also to a decrease in expression of SA and ET signalling markers [80]. This suggests that these genes and their products play a crucial role in plant defence.

S. indica presence has coincided previously with increased expression of terpene synthases [81]. In barley roots, S. indica colonisation appeared to induce expression of kaurene synthases, involved in biosynthesis of phytohormones and defence specialised metabolites. In addition, silencing of these genes in mutant lines resulted in a reduced colonisation by the endophyte, suggesting that the compounds produced play a role in establishing a successful interaction between the plant and the endophyte [81].

In the leaves of colonised plants, two terpene synthase genes were downregulated (TPS5 and TPS9), probably due to downregulation of a transcription factor that regulates their expression (SlMYC1, Solyc08g005050.3.1) [82] (Supplementary Table S14). Additionally, a recently characterised sesquiterpene synthase gene, TPS51, was the only one significantly upregulated in leaves of $S$. indica-inoculated plants. Transcripts of this gene have been detected previously in leaf tissues treated with various pathogens [83]. TPS51 encodes a terpene synthase that catalyses the formation of mostly $(E)$-nerolidol from $(E, E)$ FPP and several sesquiterpenes ( $\alpha$-bisabolol, (Z)-nerolidol, $\alpha$-bisabolene, $\beta$-bisabolene, and (Z)- $\beta$-farnesene) from (Z,Z)-FPP [52]. Although there is no ecological role assigned to these compounds, it is likely that they could act as infection alarms, warning neighbouring plants about microbial intruders in the roots $[84,85]$.

\section{Conclusions}

Plant specialised metabolites are important for adaptation and interaction with the environment, serving as defence compounds against microorganisms or other competing plants, or as signal molecules, attracting pollinators or seed dispersal animals. However, this class of compounds is activated not only in case of pathogen or predator attacks but also after endophytic colonisation, as seen here. In this case, tomato plants respond to $S$. indica colonisation by overexpressing specific biosynthetic pathways of lignin-derived compounds, polyacetylenes, and terpenes and by lowering expression of glycoalkaloid and phenylpropanoid biosynthesis. This transcriptional regulation of plant specialised metabolism in the roots can generally be explained as an attempt by the host to slow down uncontrolled expansion of the fungus by activating production of certain defence compounds and to save up resources by shutting down others. The general signalling alarm starting in the roots due to $S$. indica colonisation and transferring the information of a root intruder throughout the whole plant could be the reason why we observed similar expression patterns in the leaves of colonised plants. This activation or downregulation of specialised metabolism in the aerial parts of an endophyte-colonised plant can affect symbiotic relations with organisms of the surrounding environment but it can also be used in developing diagnostic tools that detect microbial infection/colonisation. Since establishment of any plant-microbe association involves communication through chemical compounds, it is crucial to understand how their biosynthesis is regulated and elucidate their role in the interaction in order to fully understand symbiotic events.

Supplementary Materials: The following are available online at https:/ /www.mdpi.com/article/10 $.3390 /$ microorganisms10010194/s1: Table S1. Overview of the total number of clean reads generated after filtering and the read mapping rates to S. lycopersicum and S. indica genome; Table S2. GO terms enriched in statistically upregulated genes ( $\geq 2$ fold change) in leaves of tomato plants colonised by $S$. indica; Table S3. GO terms enriched in statistically downregulated genes ( $>2$ fold change) in leaves of tomato plants colonised by S. indica; Table S4. GO terms enriched in statistically upregulated genes ( $\geq 2$ fold change) in tomato roots colonised by S. indica; Table S5. GO terms enriched in statistically 
downregulated genes ( $\geq 2$ fold change) in tomato roots colonised by $S$. indica; Table S5. GO terms enriched in statistically downregulated genes ( $\geq 2$ fold change) in tomato roots colonised by S. indica; Table S6. Key genes involved in the biosynthesis of sterols and glycoalkaloids in tomato plants; Table S7. Key genes involved in the biosynthesis of shikimate, chorismate, and phenolic compounds in tomato plants; Table S8. Key genes involved in the biosynthesis of flavonoids, flavonols, and anthocyanins in tomato plants; Table S9. Key genes involved in the biosynthesis of lignin and hydroxycinnamic acids in tomato plants; Table S10. Putative fatty-acid desaturases expressed in leaves and roots in tomato plants; Table S11. Genes involved in the mevalonate (MVA) and methylerythritol 4phosphate (MEP) pathway in tomato; Table S12. Genes encoding for trans- and cis-prenyltransferases involved in precursor biosynthesis of terpenes in tomato; Table S13. Terpene synthase gene family in tomato; Table S14. Transcription factors considered to be involved in terpene biosynthesis in tomato; Table S15. Primer list; Table S16. Key genes involved in jasmonic acid (JA) biosynthesis and signalling in tomato plants; Table S17. Key genes involved in salicylic acid (SA) biosynthesis and signalling in tomato plants; Figure S1. REVIGO scatter plot showing the selected GO terms enriched (FDR-corrected $p \leq 0.05$ ) in the significantly (A) upregulated and (B) downregulated genes in leaves of S. indica-colonised plants; Figure S2. REVIGO scatter plot showing selected GO terms enriched (simulation-corrected $p \leq 0.05$ ) in the significantly (A) upregulated and (B) downregulated genes in roots colonised by $S$. indica; Figure S3. Effect of $S$. indica colonisation on the expression of genes involved in the JA and SA biosynthesis and signalling pathways; Figure S4. Expression ratio of tomato TPSs in leaves of colonised compared to leaves of endophyte-free plants. Supplementary File S1: DESeq2 analysis. (baseMean, mean of normalised counts for all samples; $\log _{2}$ fold change, $\log _{2}$ fold change (MLE): tissue_condition LS vs. LC OR RS vs. RC; lfcSE, standard error: tissue condition LS vs. LC OR RS vs. RC; stat, Wald statistic: tissue condition LS vs. LC OR RS vs. RC; $p$-value, Wald test $p$-value: tissue condition LS vs. LC OR RS vs. RC; $p$-adj, BH-adjusted p-values (References [86-91] are cited in Supplementary Materials).

Author Contributions: Conceptualisation, F.N. and B.H.; methodology, validation, formal analysis, and investigation, F.N. and S.R.J.; resources, D.B.C.; writing-original draft preparation, F.N. and S.R.J.; writing—review and editing, all authors.; visualisation, F.N.; supervision, B.H., B.J., H.J.L.J. and D.B.C.; funding acquisition, B.J., H.J.L.J. and D.B.C. All authors read and agreed to the published version of the manuscript.

Funding: This project received funding from the European Union's Horizon 2020 research and innovation programme under the Marie Skłodowska-Curie grant agreement No. 676480. This material reflects only the authors' view, and the Research Executive Agency is not responsible for any use that may be made of the information it contains.

Institutional Review Board Statement: Not applicable.

Informed Consent Statement: Not applicable.

Data Availability Statement: Raw data in the form of FASTQ files generated by the RNA sequencing are deposited in the NCBI Sequence Read Archive (SRA) under the BioProject accession number PRJNA789108 (https:/ / www.ncbi.nlm.nih.gov/bioproject/PRJNA789108).

Acknowledgments: We would like to thank Professor Philipp Franken (Friedrich-Schiller University, Jena, Germany) for providing the Serendipita indica isolate DSM 11827 and Professor Frank Takken (University of Amsterdam, Amsterdam, The Netherlands) for seeds of Solanum lycopersicum cv. Moneymaker.

Conflicts of Interest: The authors declare no conflict of interest.

\section{References}

1. Remy, W.; Taylor, T.N.; Hass, H.; Kerp, H. Four hundred-million-year-old vesicular arbuscular mycorrhizae. Plant Biol. 1994, 91, 11841-11843. [CrossRef]

2. Selosse, M.A.; Strullu-Derrien, C.; Martin, F.M.; Kamoun, S.; Kenrick, P. Plants, fungi and oomycetes: A 400-million year affair that shapes the biosphere. New Phytol. 2015, 206, 501-506. [CrossRef]

3. Martin, F.M.; Uroz, S.; Barker, D.G. Ancestral alliances: Plant mutualistic symbioses with fungi and bacteria. Science 2017, 356, eaad4501. [CrossRef]

4. Newton, A.C.; Fitt, B.D.L.; Atkins, S.D.; Walters, D.R.; Daniell, T.J. Pathogenesis, parasitism and mutualism in the trophic space of microbe-plant interactions. Trends Microbiol. 2010, 18, 365-373. [CrossRef] 
5. Brusamarello-Santos, L.C.C.; Alberton, D.; Valdameri, G.; Camilios-Neto, D.; Covre, R.; Lopes, K.d.P.; Zibetti Tadra-Sfeir, M.; Faoro, H.; Adele Monteiro, R.; Barbosa-Silva, A.; et al. Modulation of defence and iron homeostasis genes in rice roots by the diazotrophic endophyte Herbaspirillum Seropedicae. Sci. Rep. 2019, 9, 10573. [CrossRef]

6. Lareen, A.; Burton, F.; Schäfer, P. Plant root-microbe communication in shaping root microbiomes. Plant Mol. Biol. 2016, 90, 575-587. [CrossRef]

7. Chagas, F.O.; Pessotti, R.D.C.; Caraballo-Rodríguez, A.M.; Pupo, M.T. Chemical signaling involved in plant-microbe interactions. Chem. Soc. Rev. 2018, 47, 1652-1704. [CrossRef]

8. Etalo, D.W.; Jeon, J.-S.; Raaijmakers, J.M. Modulation of plant chemistry by beneficial root microbiota. Nat. Prod. Rep. 2018, 35, 398-409. [CrossRef] [PubMed]

9. Rosa, E.; Woestmann, L.; Biere, A.; Saastamoinen, M. A plant pathogen modulates the effects of secondary metabolites on the performance and immune function of an insect herbivore. Oikos 2018, 127, 1539-1549. [CrossRef]

10. Hiruma, K. Roles of Plant-Derived Secondary Metabolites during Interactions with Pathogenic and beneficial microbes under conditions of environmental stress. Microorganisms 2019, 7, 362. [CrossRef] [PubMed]

11. Rasool, S.; Vidkjær, N.H.; Hooshmand, K.; Jensen, B.; Fomsgaard, I.S.; Meyling, N. V Seed inoculations with entomopathogenic fungi affect aphid populations coinciding with modulation of plant secondary metabolite profiles across plant families. New Phytol. 2021, 229, 1715-1727. [CrossRef]

12. Pusztahelyi, T.; Holb, I.J.; Pócsi, I. Secondary metabolites in fungus-plant interactions. Front. Plant Sci. 2015, 6, 1-23. [CrossRef] [PubMed]

13. Pascale, A.; Vinale, F.; Manganiello, G.; Nigro, M.; Lanzuise, S.; Ruocco, M.; Marra, R.; Lombardi, N.; Woo, S.L.; Lorito, M Trichoderma and its secondary metabolites improve yield and quality of grapes. Crop Prot. 2017, 92, 176-181. [CrossRef]

14. Akum, F.N.; Steinbrenner, J.; Biedenkopf, D.; Imani, J.; Kogel, K.-H. The Piriformospora indica effector PIIN_08944 promotes the mutualistic Sebacinalean symbiosis. Front. Plant Sci. 2015, 6, 1-12. [CrossRef] [PubMed]

15. Narayan, O.P.; Verma, N.; Jogawat, A.; Dua, M.; Johri, A.K. Sulfur transfer from the endophytic fungus Serendipita indica improves maize growth and requires the sulfate transporter SiSulT. Plant Cell 2021, 33, 1268-1285. [CrossRef] [PubMed]

16. Pérez-Alonso, M.-M.; Guerrero-Galán, C.; Scholz, S.S.; Kiba, T.; Sakakibara, H.; Ludwig-Müller, J.; Krapp, A.; Oelmüller, R.; Vicente-Carbajosa, J.; Pollmann, S. Harnessing symbiotic plant-fungus interactions to unleash hidden forces from extreme plant ecosystems. J. Exp. Bot. 2020, 71, 3865-3877. [CrossRef]

17. Zuccaro, A.; Lahrmann, U.; Güldener, U.; Langen, G.; Pfiffi, S.; Biedenkopf, D.; Wong, P.; Samans, B.; Grimm, C.; Basiewicz, M.; et al. Endophytic life strategies decoded by genome and transcriptome analyses of the mutualistic root symbiont Piriformospora indica. PLoS Pathog. 2011, 7, 1-26. [CrossRef]

18. Jacobs, S.; Zechmann, B.; Molitor, A.; Trujillo, M.; Petutschnig, E.; Lipka, V.; Kogel, K.-H.; Schafer, P. Broad-spectrum suppression of innate immunity is required for colonization of Arabidopsis roots by the fungus Piriformospora indica. Plant Physiol. 2011, 156, 726-740. [CrossRef]

19. Schäfer, P.; Pfiffi, S.; Voll, L.M.; Zajic, D.; Chandler, P.M.; Waller, F.; Scholz, U.; Pons-Kühnemann, J.; Sonnewald, S.; Sonnewald, U.; et al. Manipulation of plant innate immunity and gibberellin as factor of compatibility in the mutualistic association of barley roots with Piriformospora indica. Plant J. 2009, 59, 461-474. [CrossRef]

20. Hilbert, M.; Voll, L.M.; Ding, Y.; Hofmann, J.; Sharma, M.; Zuccaro, A. Indole derivative production by the root endophyte Piriformospora indica is not required for growth promotion but for biotrophic colonization of barley roots. New Phytol. 2012, 196, 520-534. [CrossRef]

21. Bajaj, R.; Huang, Y.; Gebrechristos, S.; Mikolajczyk, B.; Brown, H.; Prasad, R.; Varma, A.; Bushley, K.E. Transcriptional responses of soybean roots to colonization with the root endophytic fungus Piriformospora indica reveals altered phenylpropanoid and secondary metabolism. Sci. Rep. 2018, 8, 10227. [CrossRef] [PubMed]

22. Liu, B.; Liu, X.; Liu, F.; Ma, H.; Ma, B.; Zhang, W.; Peng, L. Growth improvement of Lolium multiflorum Lam. induced by seed inoculation with fungus suspension of Xerocomus badius and Serendipita indica. AMB Express 2019, 9, 145. [CrossRef] [PubMed]

23. Fakhro, A.; Andrade-Linares, D.R.; von Bargen, S.; Bandte, M.; Büttner, C.; Grosch, R.; Schwarz, D.; Franken, P. Impact of Piriformospora indica on tomato growth and on interaction with fungal and viral pathogens. Mycorrhiza 2010, 20, 191-200. [CrossRef] [PubMed]

24. Xu, L.; Wang, A.; Wang, J.; Wei, Q.; Zhang, W. Piriformospora indica confers drought tolerance on Zea mays L. through enhancement of antioxidant activity and expression of drought-related genes. Crop J. 2017, 5, 251-258. [CrossRef]

25. Cheng, C.; Li, D.; Qi, Q.; Sun, X.; Anue, M.R.; David, B.M.; Zhang, Y.; Hao, X.; Zhang, Z.; Lai, Z. The root endophytic fungus Serendipita indica improves resistance of banana to Fusarium oxysporum f. sp. cubense tropical race 4. Eur. J. Plant Pathol. 2020, 156, 87-100. [CrossRef]

26. Vadassery, J.; Ritter, C.; Venus, Y.; Camehl, I.; Varma, A.; Shahollari, B.; Novák, O.; Strnad, M.; Ludwig-Müller, J.; Oelmüller, R. The role of auxins and cytokinins in the mutualistic interaction between Arabidopsis and Piriformospora indica. Mol. Plant-Microbe Interact. 2008, 21, 1371-1383. [CrossRef]

27. Yadav, V.; Kumar, M.; Kumar Deep, D.; Kumar, H.; Sharma, R.; Tripathi, T.; Tuteja, N.; Kumar Saxena, A.; Kumar Johri, A. A phosphate transporter from the root endophytic fungus Piriformospora indica plays a role in phosphate transport to the host plant. J. Biol. Chem. 2010, 285, 26532-26544. [CrossRef] 
28. Xu, L.; Wu, C.; Oelmüller, R.; Zhang, W. Role of phytohormones in Piriformospora indica-induced growth promotion and stress tolerance in plants: More questions than answers. Front. Microbiol. 2018, 9, 1-13. [CrossRef]

29. Das, A.; Kamal, S.; Shakil, N.A.; Sherameti, I.; Oelmüller, R.; Dua, M.; Tuteja, N.; Johri, A.K.; Varma, A. The root endophyte fungus Piriformospora indica leads to early flowering, higher biomass and altered secondary metabolites of the medicinal plant, Coleus forskohlii. Plant Signal. Behav. 2012, 7, 103-112. [CrossRef]

30. Satheesan, J.; Narayanan, A.K.; Sakunthala, M. Induction of root colonization by Piriformospora indica leads to enhanced asiaticoside production in Centella asiatica. Mycorrhiza 2012, 22, 195-202. [CrossRef]

31. Sharma, G.; Agrawal, V. Marked enhancement in the artemisinin content and biomass productivity in Artemisia annua L. shoots co-cultivated with Piriformospora indica. World J. Microbiol. Biotechnol. 2013, 29, 1133-1138. [CrossRef] [PubMed]

32. Bajaj, R.; Agarwal, A.; Rajpal, K.; Asthana, S.; Prasad, R.; Kharkwal, A.C.; Kumar, R.; Sherameti, I.; Oelmüller, R.; Varma, A.; et al. Co-cultivation of Curcuma longa with Piriformospora indica enhances the yield and active ingredients. Am. J. Curr. Microbiol. 2014, 2, 6-17.

33. Ahuja, I.; Kissen, R.; Bones, A.M. Phytoalexins in defense against pathogens. Trends Plant Sci. 2012, 17, 73-90. [CrossRef] [PubMed]

34. FAOSTAT. 2019. Available online: www.fao.org/faostat/en/\#data/QCL (accessed on 9 December 2021).

35. De Wit, P.J.G.M.; Kodde, E. Induction of polyacetylenic phytoalexins in Lycopersicon esculentum after inoculation with Cladosporium fulvum (syn. Fulvia fulva). Physiol. Plant Pathol. 1981, 18, 143-148. [CrossRef]

36. Duffey, S.S.; Stout, M.J. Antinutritive defenses and toxic components against insects. Arch. Insect Biochem. Physiol. 1996, 32, 3-37. [CrossRef]

37. Glas, J.; Schimmel, B.; Alba, J.; Escobar-Bravo, R.; Schuurink, R.; Kant, M. Plant glandular trichomes as targets for breeding or engineering of resistance to herbivores. Int. J. Mol. Sci. 2012, 13, 17077-17103. [CrossRef] [PubMed]

38. Käfer, E. Meiotic and mitotic recombination in Aspergillus and its chromosomal aberrations. Adv. Genet. 1977, $19,33-131$. [CrossRef]

39. BBMap. Available online: www.sourceforge.net/projects/bbmap/ (accessed on 20 December 2018).

40. Patro, R.; Duggal, G.; Love, M.I.; Irizarry, R.A.; Kingsford, C. Salmon provides fast and bias-aware quantification of transcript expression. Nat. Methods 2017, 14, 417-419. [CrossRef]

41. International Tomato Genome Sequencing Project. Available online: www.solgenomics.net/organism/Solanum_lycopersicum/ genome (accessed on 25 December 2018).

42. Love, M.I.; Huber, W.; Anders, S. Moderated estimation of fold change and dispersion for RNA-seq data with DESeq2. Genome Biol. 2014, 15, 550. [CrossRef]

43. Joung, J.-G.; Corbett, A.M.; Fellman, S.M.; Tieman, D.M.; Klee, H.J.; Giovannoni, J.J.; Fei, Z. Plant MetGenMAP: An integrative analysis system for plant systems biology. Plant Physiol. 2009, 151, 1758-1768. [CrossRef]

44. R Version 3.4.1. Available online: www.cran.r-project.org/bin/windows/base/old/3.4.1/ (accessed on 6 July 2018).

45. Supek, F.; Bošnjak, M.; Škunca, N.; Šmuc, T. REVIGO summarizes and visualizes long lists of gene ontology terms. PLoS ONE 2011, 6, e21800. [CrossRef]

46. Itkin, M.; Heinig, U.; Tzfadia, O.; Bhide, A.J.; Shinde, B.; Cardenas, P.D.; Bocobza, S.E.; Unger, T.; Malitsky, S.; Finkers, R.; et al. Biosynthesis of antinutritional alkaloids in solanaceous crops is mediated by clustered genes. Science 2013, 341, 175-179. [CrossRef]

47. Cárdenas, P.D.; Sonawane, P.D.; Pollier, J.; Vanden Bossche, R.; Dewangan, V.; Weithorn, E.; Tal, L.; Meir, S.; Rogachev, I.; Malitsky, S.; et al. GAME9 regulates the biosynthesis of steroidal alkaloids and upstream isoprenoids in the plant mevalonate pathway. Nat. Commun. 2016, 7, 1-16. [CrossRef] [PubMed]

48. Itkin, M.; Rogachev, I.; Alkan, N.; Rosenberg, T.; Malitsky, S.; Masini, L.; Meir, S.; Iijima, Y.; Aoki, K.; de Vos, R.; et al. GLYCOALKALOID METABOLISM1 is required for steroidal alkaloid glycosylation and prevention of phytotoxicity in tomato. Plant Cell 2011, 23, 4507-4525. [CrossRef] [PubMed]

49. Martinez, V.; Mestre, T.C.; Rubio, F.; Girones-Vilaplana, A.; Moreno, D.A.; Mittler, R.; Rivero, R.M. Accumulation of flavonols over hydroxycinnamic acids favors oxidative damage protection under abiotic stress. Front. Plant Sci. 2016, 7, 1-17. [CrossRef]

50. Fernandez-Moreno, J.-P.; Tzfadia, O.; Forment, J.; Presa, S.; Rogachev, I.; Meir, S.; Orzaez, D.; Aharoni, A.; Granell, A. Characterization of a new pink-fruited tomato mutant results in the identification of a null allele of the SIMYB12 transcription factor. Plant Physiol. 2016, 171, 1821-1836. [CrossRef]

51. Jeon, J.E.; Kim, J.-G.; Fischer, C.R.; Mehta, N.; Dufour-Schroif, C.; Wemmer, K.; Mudgett, M.B.; Sattely, E. A pathogen-responsive gene cluster for highly modified fatty acids in tomato. Cell 2020, 180, 176-187.e19. [CrossRef] [PubMed]

52. Zhou, F.; Pichersky, E. The complete functional characterisation of the terpene synthase family in tomato. New Phytol. 2020, 226, 1341-1360. [CrossRef]

53. Schilmiller, A.L.; Schauvinhold, I.; Larson, M.; Xu, R.; Charbonneau, A.L.; Schmidt, A.; Wilkerson, C.; Last, R.L.; Pichersky, E. Monoterpenes in the glandular trichomes of tomato are synthesized from a neryl diphosphate precursor rather than geranyl diphosphate. Proc. Natl. Acad. Sci. USA 2009, 106, 10865-10870. [CrossRef]

54. Falara, V.; Akhtar, T.A.; Nguyen, T.T.H.; Spyropoulou, E.A.; Bleeker, P.M.; Schauvinhold, I.; Matsuba, Y.; Bonini, M.E.; Schilmiller, A.L.; Last, R.L.; et al. The tomato terpene synthase gene family. Plant Physiol. 2011, 157, 770-789. [CrossRef] 
55. Van Schie, C.C.N.; Haring, M.A.; Schuurink, R.C. Tomato linalool synthase is induced in trichomes by jasmonic acid. Plant Mol. Biol. 2007, 64, 251-263. [CrossRef]

56. Colby, S.M.; Crock, J.; Dowdle-Rizzo, B.; Lemaux, P.G.; Croteau, R. Germacrene C synthase from Lycopersicon esculentum cv. VFNT Cherry tomato: cDNA isolation, characterization, and bacterial expression of the multiple product sesquiterpene cyclase. Biochemistry 1998, 95, 2216-2221. [CrossRef]

57. Molitor, A.; Zajic, D.; Voll, L.M.; Pons-Kühnemann, J.; Samans, B.; Kogel, K.-H.; Waller, F. Barley leaf transcriptome and metabolite analysis reveals new aspects of compatibility and Piriformospora indica-mediated systemic induced resistance to powdery mildew. Mol. Plant-Microbe Interact. 2011, 24, 1427-1439. [CrossRef]

58. Strehmel, N.; Mönchgesang, S.; Herklotz, S.; Krüger, S.; Ziegler, J.; Scheel, D. Piriformospora indica stimulates root metabolism of Arabidopsis thaliana. Int. J. Mol. Sci. 2016, 17, 1091. [CrossRef] [PubMed]

59. Byrne, M.E. A role for the ribosome in development. Trends Plant Sci. 2009, 14, 512-519. [CrossRef]

60. Milner, S.E.; Brunton, N.P.; Jones, P.W.; O' Brien, N.M.; Collins, S.G.; Maguire, A.R. Bioactivities of glycoalkaloids and their aglycones from Solanum species. J. Agric. Food Chem. 2011, 59, 3454-3484. [CrossRef] [PubMed]

61. Rasool, S.; Cárdenas, P.D.; Pattison, D.I.; Jensen, B.; Meyling, N.V. Isolate-specific effect of entomopathogenic endophytic fungi on population growth of two-spotted spider mite (Tetranychus urticae Koch) and levels of steroidal glycoalkaloids in tomato. J. Chem. Ecol. 2021, 47, 476-488. [CrossRef] [PubMed]

62. Kozukue, N.; Han, J.-S.; Lee, K.-R.; Friedman, M. Dehydrotomatine and $\alpha$-tomatine content in tomato fruits and vegetative plant tissues. J. Agric. Food Chem. 2004, 52, 2079-2083. [CrossRef] [PubMed]

63. Zhang, H.; Hedhili, S.; Montiel, G.; Zhang, Y.; Chatel, G.; Pré, M.; Gantet, P.; Memelink, J. The basic helix-loop-helix transcription factor CrMYC2 controls the jasmonate-responsive expression of the ORCA genes that regulate alkaloid biosynthesis in Catharanthus roseus. Plant J. 2011, 67, 61-71. [CrossRef]

64. Nowacki, E.; Jurzysta, M.; Gorski, P.; Nowacka, D.; Waller, G.R. Effect of nitrogen nutrition on alkaloid metabolism in plants. Biochem. Und Physiol. Pflanz. 1976, 169, 231-240. [CrossRef]

65. Lahrmann, U.; Ding, Y.; Banhara, A.; Rath, M.; Hajirezaei, M.R.; Döhlemann, S.; von Wirén, N.; Parniske, M.; Zuccaro, A Host-related metabolic cues affect colonization strategies of a root endophyte. Proc. Natl. Acad. Sci. USA 2013, 110, 13965-13970. [CrossRef]

66. Niggeweg, R.; Michael, A.J.; Martin, C. Engineering plants with increased levels of the antioxidant chlorogenic acid. Nat. Biotechnol. 2004, 22, 746-754. [CrossRef]

67. Quiroga, M.; Guerrero, C.; Botella, M.A.; Barceló, A.; Amaya, I.; Medina, M.I.; Alonso, F.J.; de Forchetti, S.M.; Tigier, H.; Valpuesta, V. A tomato peroxidase involved in the synthesis of lignin and suberin. Plant Physiol. 2000, 122, 1119-1128. [CrossRef]

68. Lahrmann, U.; Strehmel, N.; Langen, G.; Frerigmann, H.; Leson, L.; Ding, Y.; Scheel, D.; Herklotz, S.; Hilbert, M.; Zuccaro, A Mutualistic root endophytism is not associated with the reduction of saprotrophic traits and requires a noncompromised plant innate immunity. New Phytol. 2015, 207, 841-857. [CrossRef] [PubMed]

69. Tashackori, H.; Sharifi, M.; Ahmadian Chashmi, N.; Safaie, N.; Behmanesh, M. Induced-differential changes on lignan and phenolic acid compounds in Linum album hairy roots by fungal extract of Piriformospora indica. Plant Cell Tissue Organ Cult. 2016, 127, 187-194. [CrossRef]

70. Busta, L.; Yim, W.C.; LaBrant, E.W.; Wang, P.; Grimes, L.; Malyszka, K.; Cushman, J.C.; Santos, P.; Kosma, D.K.; Cahoon, E.B. Identification of genes encoding enzymes catalyzing the early steps of carrot polyacetylene biosynthesis. Plant Physiol. 2018, 178, 1507-1521. [CrossRef] [PubMed]

71. Badami, R.C.; Patil, K.B. Structure and occurrence of unusual fatty acids in minor seed oils. Prog. Lipid Res. 1980, 19, 119-153. [CrossRef]

72. Bleeker, P.M.; Diergaarde, P.J.; Ament, K.; Guerra, J.; Weidner, M.; Schutz, S.; de Both, M.T.J.; Haring, M.A.; Schuurink, R.C. The role of specific tomato volatiles in tomato-whitefly interaction. Plant Physiol. 2009, 151, 925-935. [CrossRef]

73. Van Poecke, R.M.P.; Posthumus, M.A.; Dicke, M. Herbivore-induced volatile production by Arabidopsis thaliana leads to attraction of the parasitoid Cotesia rubecula: Chemical, behavioral, and gene-expression analysis. J. Chem. Ecol. 2001, 27, 1911-1928. [CrossRef]

74. Rebers, M.; Kaneta, T.; Kawaide, H.; Yamaguchi, S.; Yang, Y.Y.; Imai, R.; Sekimoto, H.; Kamiya, Y. Regulation of gibberellin biosynthesis genes during flower and early fruit development of tomato. Plant J. 1999, 17, 241-250. [CrossRef]

75. Schilmiller, A.L.; Miner, D.P.; Larson, M.; McDowell, E.; Gang, D.R.; Wilkerson, C.; Last, R.L. Studies of a biochemical factory: Tomato trichome deep expressed sequence tag sequencing and proteomics. Plant Physiol. 2010, 153, 1212-1223. [CrossRef]

76. Bleeker, P.M.; Spyropoulou, E.A.; Diergaarde, P.J.; Volpin, H.; De Both, M.T.J.; Zerbe, P.; Bohlmann, J.; Falara, V.; Matsuba, Y.; Pichersky, E.; et al. RNA-seq discovery, functional characterization, and comparison of sesquiterpene synthases from Solanum lycopersicum and Solanum habrochaites trichomes. Plant Mol. Biol. 2011, 77, 323-336. [CrossRef]

77. Matsuba, Y.; Zi, J.; Jones, A.D.; Peters, R.J.; Pichersky, E. Biosynthesis of the diterpenoid lycosantalonol via nerylneryl diphosphate in Solanum lycopersicum. PLoS ONE 2015, 10, e0119302. [CrossRef] [PubMed]

78. Zouari, I.; Salvioli, A.; Chialva, M.; Novero, M.; Miozzi, L.; Tenore, G.; Bagnaresi, P.; Bonfante, P. From root to fruit: RNA-Seq analysis shows that arbuscular mycorrhizal symbiosis may affect tomato fruit metabolism. BMC Genom. 2014, 15, 1-19. [CrossRef] [PubMed] 
79. Lee, H.-A.; Kim, S.; Kim, S.; Choi, D. Expansion of sesquiterpene biosynthetic gene clusters in pepper confers nonhost resistance to the Irish potato famine pathogen. New Phytol. 2017, 215, 1132-1143. [CrossRef]

80. Lin, Y.M.; Shih, S.L.; Lin, W.C.; Wu, J.W.; Chen, Y.T.; Hsieh, C.Y.; Guan, L.C.; Lin, L.; Cheng, C.P. Phytoalexin biosynthesis genes are regulated and involved in plant response to Ralstonia solanacearum infection. Plant Sci. 2014, 224, 86-94. [CrossRef] [PubMed]

81. Li, L.; Chen, X.; Ma, C.; Wu, H.; Qi, S. Piriformospora indica requires kaurene synthase activity for successful plant colonization. Plant Physiol. Biochem. 2016, 102, 151-160. [CrossRef] [PubMed]

82. Spyropoulou, E.A.; Haring, M.A.; Schuurink, R.C. RNA sequencing on Solanum lycopersicum trichomes identifies transcription factors that activate terpene synthase promoters. BMC Genom. 2014, 15, 1-16. [CrossRef] [PubMed]

83. Aoki, K.; Yano, K.; Suzuki, A.; Kawamura, S.; Sakurai, N.; Suda, K.; Kurabayashi, A.; Suzuki, T.; Tsugane, T.; Watanabe, M.; et al. Large-scale analysis of full-length cDNAs from the tomato (Solanum lycopersicum) cultivar Micro-Tom, a reference system for the solanaceae genomics. BMC Genom. 2010, 11, 210. [CrossRef]

84. Sharma, E.; Anand, G.; Kapoor, R. Terpenoids in plant and arbuscular mycorrhiza-reinforced defence against herbivorous insects. Ann. Bot. 2017, 119, mcw263. [CrossRef]

85. Riedlmeier, M.; Ghirardo, A.; Wenig, M.; Knappe, C.; Koch, K.; Georgii, E.; Dey, S.; Parker, J.E.; Schnitzler, J.-P.; Vlot, A.C. Monoterpenes support systemic acquired resistance within and between plants. Plant Cell 2017, 29, 1440-1459. [CrossRef] [PubMed]

86. Kim, D.; Pertea, G.; Trapnell, C.; Pimentel, H.; Kelley, R.; Salzberg, S.L. TopHat2: accurate alignment of transcriptomes in the presence of insertions, deletions and gene fusions. Genome Biol. 2013, 14, R36. [CrossRef]

87. Langmead, B.; Salzberg, S.L. Fast gapped-read alignment with Bowtie 2. Nat. Methods 2012, 9, 357-359. [CrossRef]

88. Zhang, Y.; Butelli, E.; Alseekh, S.; Tohge, T.; Rallapalli, G.; Luo, J.; Kawar, P.G.; Hill, L.; Santino, A.; Fernie, A.R.; et al. Multi-level engineering facilitates the production of phenylpropanoid compounds in tomato. Nat. Commun. 2015, 6, 1-11. [CrossRef]

89. Lin, C.Y.; Wang, J.P.; Li, Q.; Chen, H.-C.; Liu, J.; Loziuk, P.; Song, J.; Williams, C.; Muddiman, D.C.; Sederoff, R.R.; et al. 4-Coumaroyl and caffeoyl shikimic acids inhibit 4-coumaric acid:coenzyme A ligases and modulate metabolic flux for 3hydroxylation in monolignol biosynthesis of Populus trichocarpa. Mol. Plant 2015, 8, 176-187. [CrossRef]

90. Martel, C.; Zhurov, V.; Navarro, M.; Martinez, M.; Cazaux, M.; Auger, P.; Migeon, A.; Santamaria, M.E.; Wybouw, N.; Diaz, I.; et al. Tomato whole genome transcriptional response to Tetranychus urticae identifies divergence of spider mite-induced responses between tomato and Arabidopsis. Mol. Plant-Microbe Interact. 2015, 28, 343-361. [CrossRef] [PubMed]

91. Pfaffl, M.W. Relative expression software tool (REST(C)) for group-wise comparison and statistical analysis of relative expression results in real-time PCR. Nucleic Acids Res. 2002, 30, 36e. [CrossRef] [PubMed] 